\title{
During a corticotropin-releasing hormone test in healthy subjects, administration of a beta-adrenergic antagonist induced secretion of cortisol and dehydroepiandrosterone sulfate and inhibited secretion of ACTH
}

Selda Kizildere, Thomas Glück, Bettina Zietz, Jürgen Schölmerich and Rainer H Straub

Department of Internal Medicine I, University Hospital of Regensburg, 93042 Regensburg, Germany

(Correspondence should be addressed to R H Straub; Email: rainerstraub@klinik.uni-regensburg.de)

\begin{abstract}
Objective: In chronic inflammatory diseases, serum levels of dehydroepiandrosterone (DHEA) sulfate (DHEAS) are low. Interestingly, several non-inflammatory diseases display similarly low levels of DHEAS which points to other inhibitory factors such as an activated sympathetic nervous system (SNS) (e.g. in patients with heart failure, fibromyalgia, or cancer cachexia). We aimed to identify the influence of the SNS tone on stimulated adrenal steroid secretion in 16 male and 12 female healthy subjects.

Methods: One group were given oral propranolol $2 \mathrm{~h}$ before a corticotropin-releasing hormone (CRH) test, and levels of adrenocorticotropin (ACTH), cortisol, 17-hydroxyprogesterone (17OHP), androstenedione, DHEA, and DHEAS were measured.

Results: Propranolol treatment decreased heart rate (by 20\%), diastolic blood pressure (by 20\%), and plasma ACTH, and increased serum cortisol, serum DHEAS, and the molar ratio of cortisol/17OHP, cortisol/DHEA, and DHEAS/DHEA similarly in female and male subjects.

Conclusions: A $\beta$-adrenergic influence seems to decrease $\mathrm{CRH}$-stimulated cortisol in relation to ACTH and 17OHP, and decreases DHEAS in relation to DHEA. Although other workers have found $\beta$-adrenergic stimulation of steroid secretion in cultured adrenocortical cells, the overall systemic influence of the SNS via $\beta$-adrenoceptors seems to inhibit adrenal steroids under unstimulated and stimulated conditions. Sympathetic hyperactivity may be a common denominator for low levels of DHEAS in inflammatory and non-inflammatory diseases.
\end{abstract}

European Journal of Endocrinology 148 45-53

\section{Introduction}

Chronic inflammatory diseases such as rheumatoid arthritis, systemic lupus erythematosus, inflammatory bowel disease, and others are accompanied by low levels of dehydroepiandrosterone (DHEA) and its sulfated derivative DHEAS (1-8). The reason for the unexpected decrease in serum levels of adrenal androgens during chronic inflammation is not yet known. It has been proposed that proinflammatory cytokines such as tumor necrosis factor (TNF) and intra-adrenal immune cells may change the microenvironment leading to lower adrenal and gonadal hormone secretion in chronic inflammatory diseases but, up to now, no formal proof has been presented (9).

Interestingly, non-inflammatory diseases such as fibromyalgia, heart failure, cardiovascular disease, and cancer similarly display low levels of DHEAS (10-16). Under these non-inflammatory conditions, cytokines or intra-adrenal immune cells probably will not play a major role in changes in adrenal DHEAS secretion. Thus, other factors which are similarly altered in the same direction in inflammatory and non-inflammatory disease may be more relevant. The common denominator for this phenomenon in inflammatory and non-inflammatory diseases may be a hypersympathetic nervous tone which has been demonstrated several times in the mentioned diseases with low DHEAS levels (e.g. 17-22).

Since the sympathetic nervous system via $\beta$-adrenoceptors has a strong influence on adrenal hormone secretion (23), we investigated the influence of the non-selective $\beta$-adrenergic antagonist propranolol (without intrinsic sympathetic activity) on corticotropin-releasing hormone (CRH)-stimulated secretion of adrenal hormones. In contrast to two earlier studies with propranolol and CRH injection $(24,25)$ or propranolol and hypoglycemia (e.g. 24, 26, 27), this study 
extended the earlier view by consideration of molar hormone ratios such as cortisol/adrenocorticotropin (ACTH), cortisol/17-hydroxyprogesterone (17OHP), cortisol/DHEA, and DHEAS/DHEA. Furthermore, responses were separately calculated and depicted for female and male subjects.

\section{Subjects and methods}

\section{Subjects}

A total of 28 healthy subjects, 12 women (aged 25 years, range 21-33 years) and 16 men (aged 26 years, range 23-36 years), were included in this study. The subjects were checked by a 33-item questionnaire (28), which revealed that these subjects had had no severe diseases in the past and no present or current symptoms of diseases. They were not on medication, had not had prior vaccination, did not smoke or drink alcohol in excess, and their family and surgical histories were unremarkable. The questionnaire was adapted from the SENIEUR protocol (29). The women in this study were in the early to mid follicular phase of the menstrual cycle in order to be comparable to their male counterparts, and they were not taking oral contraceptives. The study was approved by the Ethics Committee of the University of Regensburg and the subjects were extensively informed about the study protocol and gave written consent. Groups with or without prior propranolol administration (see below) were not different in age (nine males without propranolol: $26 \pm 1$, seven males with prior propranolol: $26 \pm 1$, five females without prior propranolol: $27 \pm 2$, seven females with prior propranolol: $24 \pm 1$ years).

\section{Test procedure}

At $0700 \mathrm{~h}$, the study subjects had a light breakfast and they were allowed to drink mineral water during the morning. Then, they were admitted to the ambulatory research unit at $1200 \mathrm{~h}$. They were instructed to remain in a supine position for the entire duration of the test. They received an indwelling catheter in an antecubital vein at $1215 \mathrm{~h}$ (for i.v. injection of human (h) $\mathrm{CRH}$, and for withdrawing blood samples) and blood pressure was measured at the contralateral arm. They were connected to an ECG monitor, and heart rate, beat-to-beat intervals, and blood pressure were recorded. In the propranolol-treated group, $10 \mathrm{mg}$ propranolol (Dociton, Astra-Zeneca, Plankstadt, Germany) were given orally. Target heart rate and diastolic blood pressure were adjusted to levels 20\% lower than the initial value by additional propranolol tablets $(10 \mathrm{mg})$ if necessary (this occurred in only two subjects, one hour after the first administration). The first blood sample was drawn at time $-10 \mathrm{~min}(1350 \mathrm{~h})$. One hundred micrograms hCRH (Ferring Arzneimittel, Kiel, Germany) were administered i.v. as a bolus
$10 \mathrm{~min}$ later at time $0(1400 \mathrm{~h})$. Blood samples were taken at the following experimental times: $-10,+15$, $+30,+45,+90$ and $+120 \mathrm{~min}$. The samples were immediately centrifuged and plasma and serum were stored in adequate aliquots at $-80^{\circ} \mathrm{C}$. Heart rate, diastolic and systolic blood pressure, and heart rate variability during 6 deep breaths per minute (respiratory sinus arrhythmia test (30)) were recorded at the following experimental times: $-10,+5,+30,+45,+90$ and $+120 \mathrm{~min}$

All tests were started at $1400 \mathrm{~h}$ when the tonus of the hypothalamic-pituitary-adrenal (HPA) axis and of the hypothalamus-autonomic nervous system (HANS) axis were in an intermediate stage, which allowed for the investigation of either upregulation or downregulation of responses. The test ended at $1600 \mathrm{~h}$, the catheter and ECG electrodes were removed, and the subjects were observed for another $30 \mathrm{~min}$.

\section{Laboratory methods}

Several adrenal hormones were considered in order to detect major adrenal pathways of steroidogenesis. We used radioimmunometric assays for the quantitative determination of serum levels of cortisol (Coulter Immunotech, Marseilles, France; detection limit: $10 \mathrm{nmol} / \mathrm{l}$ ). Serum levels of $17 \mathrm{OHP}$ (IBL, Hamburg, Germany; detection limit: $0.3 \mathrm{nmol} / \mathrm{l}$ ), androstenedione (ASD) (IBL; detection limit: $0.13 \mathrm{nmol} / \mathrm{l})$, DHEAS (IBL; detection limit: $130 \mathrm{nmol} / \mathrm{l}$ ), DHEA (Diagnostic Systems Laboratory, Webster, TX, USA; detection limit: $0.13 \mathrm{nmol} / \mathrm{l}$ ), and plasma levels of ACTH (Sangui BioTech, Inc., CA, USA, via IBL; detection limit: $0.1 \mathrm{pmol} / \mathrm{l}$ ) were measured by enzyme immunoassays. In all tests, interassay and intra-assay variability were lower than $10 \%$.

\section{Calculation of hormone/hormone ratios}

In order to demonstrate the shift from one serum hormone to another, the molar ratio of these hormones was calculated (given without units) $(31,32)$. This procedure detects a hormonal shift through one or more adrenal enzyme steps which can demonstrate a preponderance of an adrenal pathway: cortisol/170HP for the pathway through P450c21 and P450c11 into the direction of cortisol, ASD/170H-progesterone for the 17,20lyase (2nd reaction of the P450c17) into the direction of ASD, DHEA/ASD for the $3 \beta$-hydroxysteroid dehydrogenase into the direction of DHEA, and DHEAS/DHEA for the combined reaction of the DHEA sulfotransferase and the DHEAS sulfatase into the direction of DHEAS. Finally, the molar ratio of serum cortisol/serum DHEA indicates a shift into the direction of cortisol in relation to adrenal androgens. 


\section{Statistical analysis}

Responses of the different subgroups in relation to the observation time were compared by multivariate analysis (general linear model, SPSS/PC for Windows, v.10.0.5, SPSS, Inc., Chicago, IL, USA) after having tested homogeneity of variances. Values are expressed as means \pm S.E.M. and the significance level was $P<0.05$.

\section{Results}

Inhibition of the sympathetic nervous system

In order to control inhibition of the sympathetic nervous system, heart rate, diastolic blood pressure, and heart rate variability during the respiratory sinus arrhythmia test were recorded. Figure 1 demonstrates a $20 \%$ reduction of heart rate and diastolic blood pressure and a significant reduction in heart rate variability in the respiratory sinus arrhythmia test in subjects receiving propranolol. These data indicate a clear inhibition of the sympathetic nervous system by propranolol before and during the hCRH test, irrespective of gender (Fig. 1).

\section{Plasma ACTH and serum cortisol in relation to each other}

Figure 2 demonstrates that plasma levels of ACTH were significantly lower in both male and female subjects in the group with prior propranolol administration. As compared with control subjects, in subjects with propranolol, the increase in ACTH was delayed and the ACTH peak appeared at $45 \mathrm{~min}$ irrespective of gender
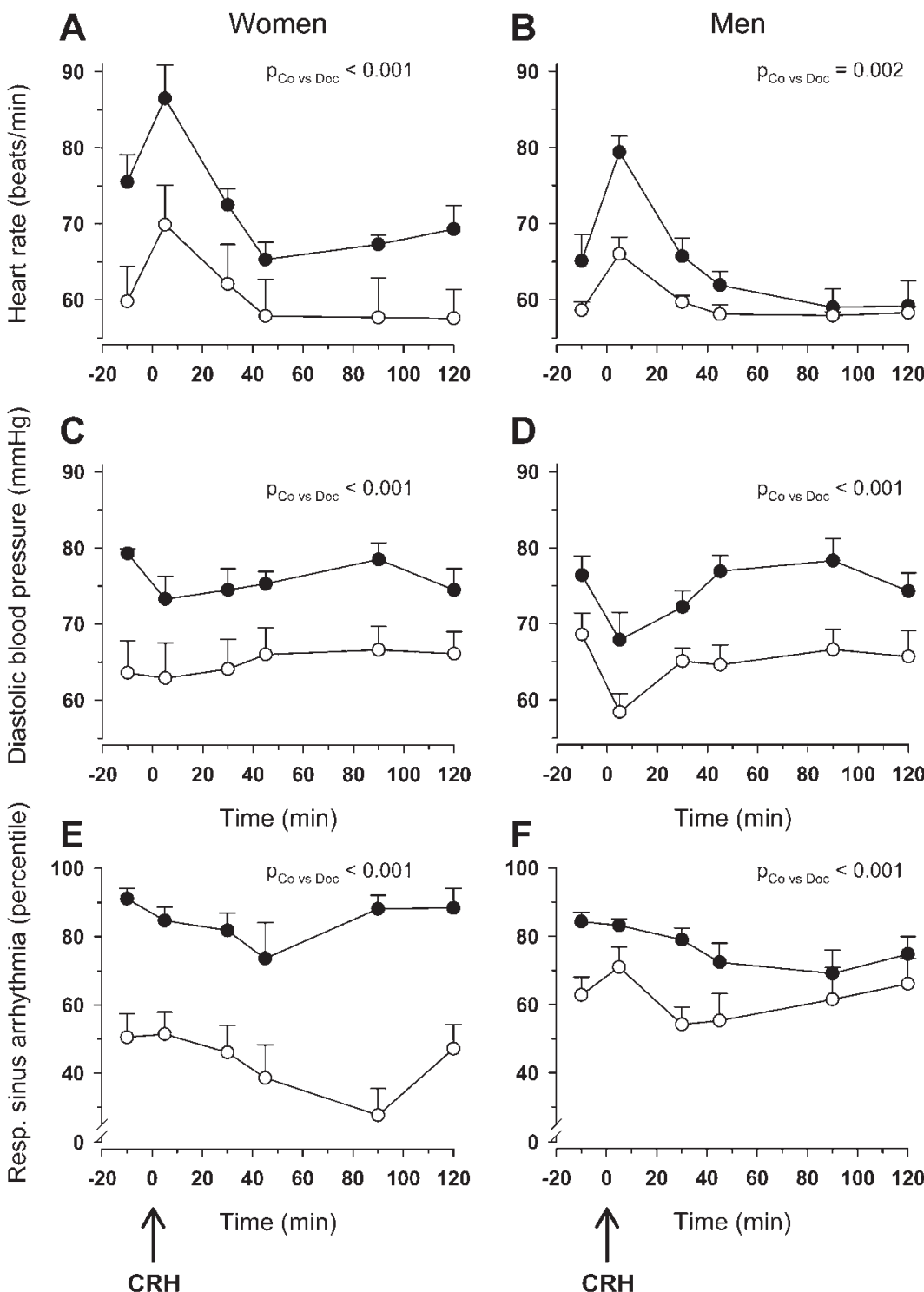

D
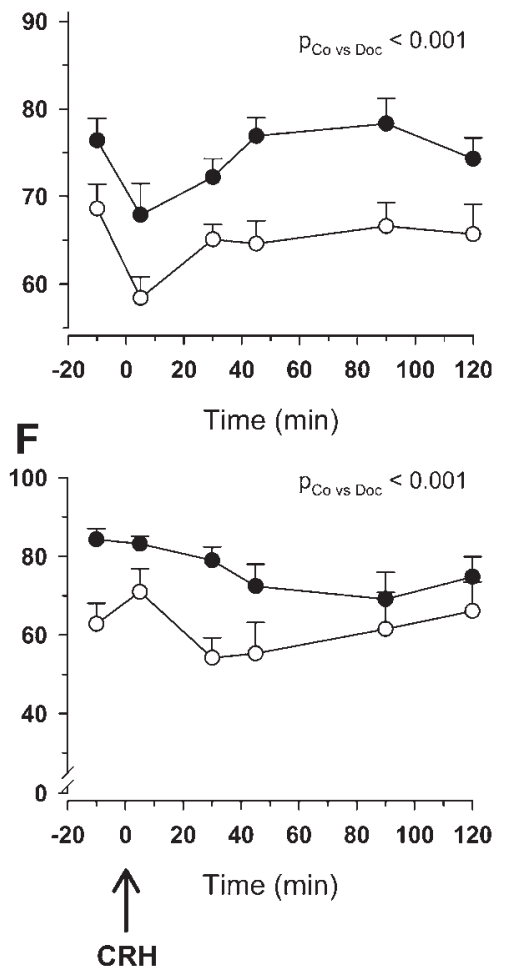

Figure 1 Time course of autonomic nervous function parameters before and during a hCRH test with or without prior propranolol administration in women and men. The figure depicts heart rate $(A, B)$, diastolic blood pressure $(C, D)$, and heart rate variability of the respiratory sinus arrhythmia test $(E, F)$. The unit of the respiratory sinus arrhythmia test is the age-corrected percentile localization, as described earlier (30). One hundred micrograms hCRH were injected at $1400 \mathrm{~h}$ and parameters were recorded at $-10,+5$, $+30,+45,+90$ and $+120 \mathrm{~min}$. Solid symbols represent data without prior propranolol administration and open symbols represent data with prior propranolol administration. Data are given as means \pm S.E.M. The $P$ value gives the significance for the comparison of the different subgroups in relation to the observation time compared by multivariate analysis (general linear model): Co, control subjects; Doc, propranolol-treated subjects. 

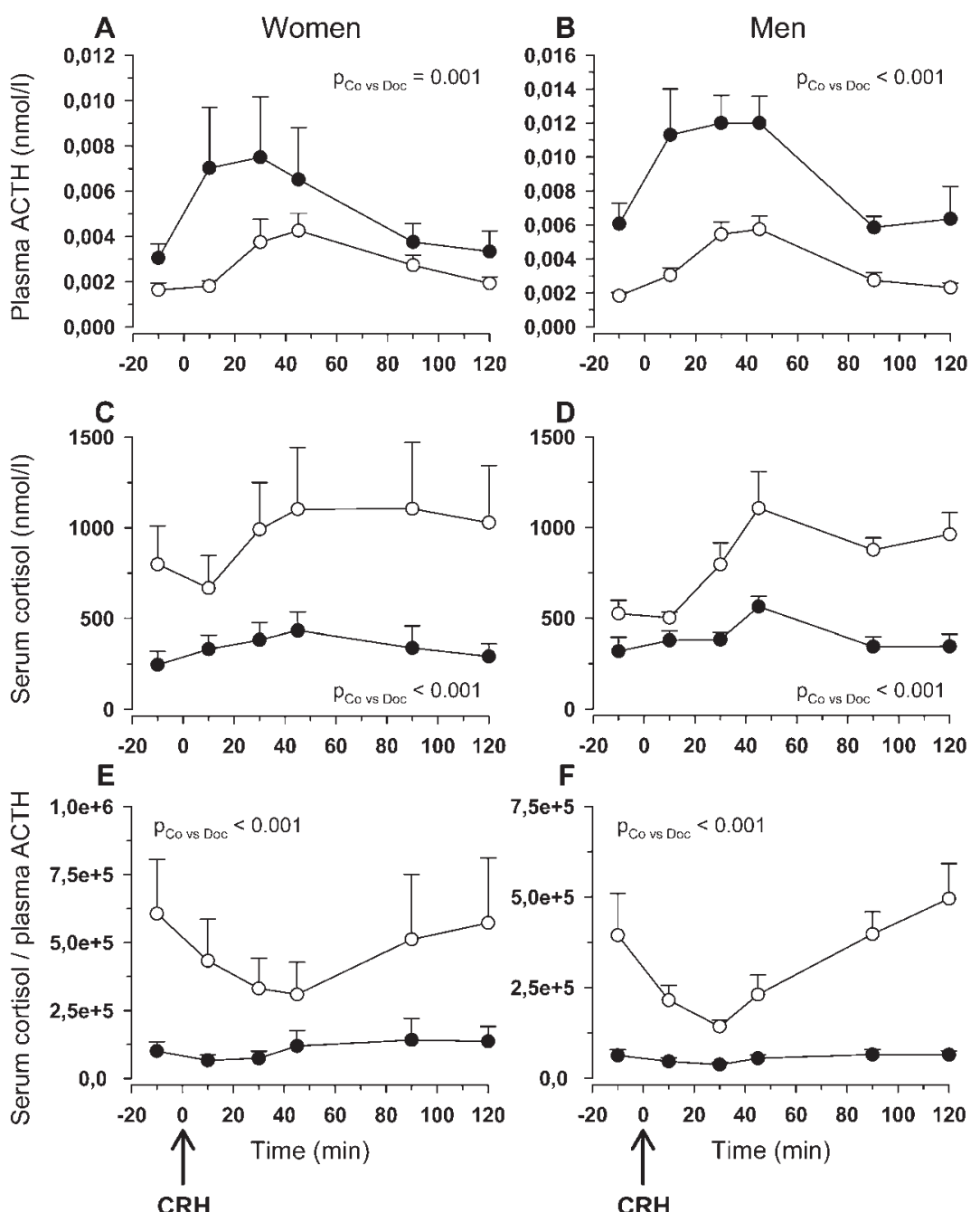

$$
\text { F }
$$

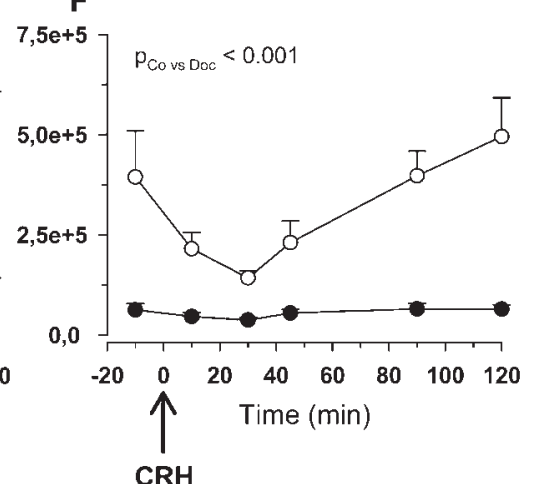

Figure 2 Time course of ACTH, cortisol, and the hormone ratio before and during a $\mathrm{hCRH}$ test with $(\mathrm{O})$ or without $(\bullet)$ prior propranolol administration in women and men. The figure depicts plasma ACTH (A, B), serum cortisol (C, D), and the ratio of serum cortisol/plasma ACTH (E, F). The molar ratio has no units. One hundred micrograms hCRH were injected at $1400 \mathrm{~h}$ and parameters were recorded at $-10,+15,+30,+45,+90$ and +120 min. Explanations for symbols, data presentation, $P$ value, and abbreviations are given in the legend to Fig. 1.

(Fig. 2A,B). In contrast, serum cortisol was significantly elevated in propranolol-treated women and men as compared with control subjects (Fig. 2C,D). Serum cortisol demonstrated the typical hCRH-dependent increase with a peak at 45 min irrespective of gender and treatment (Fig. 2C,D). This led to a significantly elevated molar cortisol to ACTH ratio in the propranolol group compared with control subjects which was independent of gender (Fig. 2E,F).

\section{The second step of P450c17 and $3 \beta$ - hydroxysteroid dehydrogenase}

Propranolol treatment did not change serum levels of ASD (Fig. 3A,B), the ratio of serum DHEA/serum ASD, or serum ASD/serum 170HP irrespective of gender (data not shown).
The adrenal steroid pathway via $P 450 c 21$ and P450c11

Women with prior propranolol administration demonstrated significantly lower serum levels of $170 \mathrm{HP}$ as compared with the control group, which was not obvious in male subjects (Fig. 3C,D). Concerning the ratio of serum cortisol/serum $170 \mathrm{HP}$, women receiving propranolol displayed a significantly elevated ratio as compared with the control group (Fig. 3E). Although smaller in size, this effect was also observed in male subjects with prior propranolol administration (Fig. 3F).

\section{The DHEA sulfotransferase and the DHEAS sulfatase reaction}

Administration of propranolol to women and men led to a significant increase in serum DHEAS (Fig. 4A,B), which was not observed for serum DHEA (Fig. 4C,D). In the propranolol group, the molar ratio of serum 

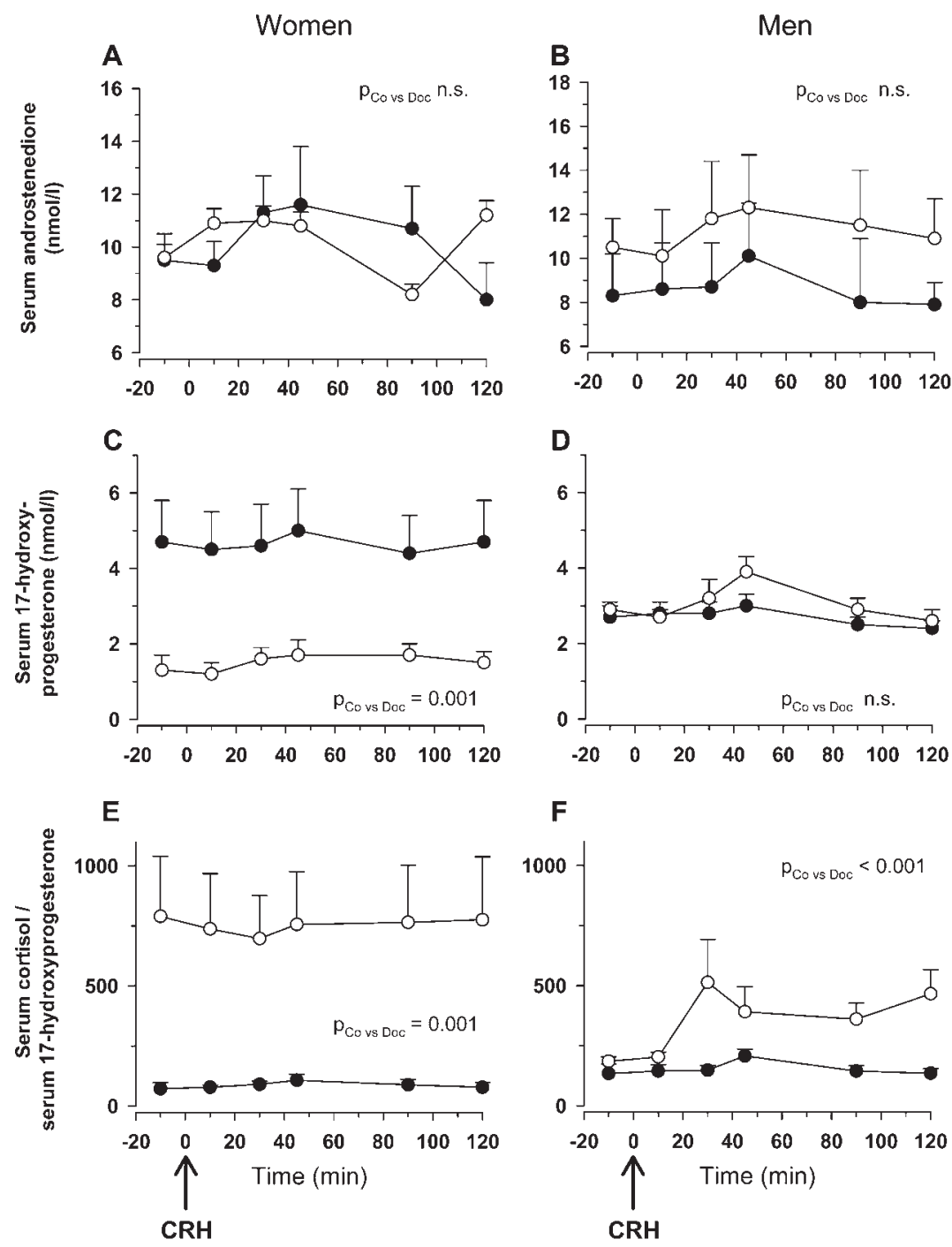

Figure 3 Time course of androstenedione, 17-hydroxyprogesterone (17OHP) and the ratio of serum cortisol/serum 17OHP before and during a hCRH test with $(\mathrm{O})$ or without $(\bullet)$ prior propranolol administration in women and men. The figure depicts serum androstenedione $(\mathrm{A}, \mathrm{B}), 17 \mathrm{OHP}(\mathrm{C}, \mathrm{D})$, and the ratio of serum cortisol/serum 17OHP (E, F). The molar ratio has no units. Procedure and explanations for symbols, data presentation, $P$ value, and abbreviations are given in the legend to Fig. 1.

DHEAS/serum DHEA was significantly elevated as compared with control subjects (Fig. 4E,F). This was independent of gender and appeared to be more significant under unstimulated than under stimulated conditions (i.e. at baseline as compared with conditions after $\mathrm{CRH}$ injection).

\section{Two main adrenal steroid pathways versus} each other: serum cortisol versus serum DHEA

Propranolol treatment increased the molar ratio of serum cortisol/serum DHEA under unstimulated and stimulated conditions in women and men (Fig. 5A,B). The propranolol-induced increase was more marked in female as compared with male subjects (Fig. 5A,B).

\section{Discussion}

To our knowledge, no other studies are available which investigated adrenal steroid pathways in a similar way with and without propranolol pre-treatment and concomitant $\mathrm{CRH}$ stimulation. One study has shown a methoxamine ( $\alpha 1$-adrenergic agonist)-induced increase of CRH-stimulated ACTH and subsequent serum cortisol increase which are compatible with our results (25). In another experiment, the unspecific $\alpha 1$,2-adrenergic antagonist, phentolamine, had no influence on $\mathrm{CRH}-$ stimulated ACTH and cortisol levels (24). Several studies induced hypoglycemia in order to activate the HPA axis and administered $\beta$-adrenergic and $\alpha$-adrenergic agonists and antagonists: four independent studies noted a propranolol-induced increase in plasma ACTH and/or serum cortisol during hypoglycemia $(24,26,27,33)$. However, these groups did not 

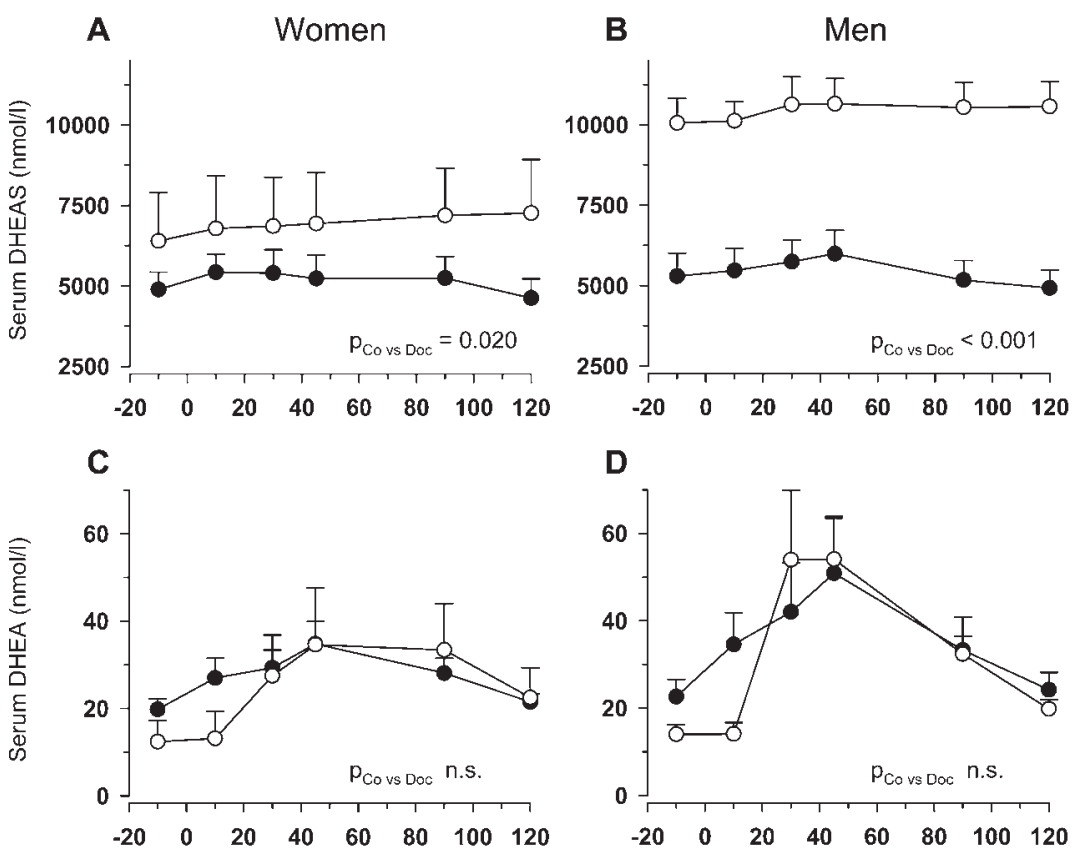

E

F
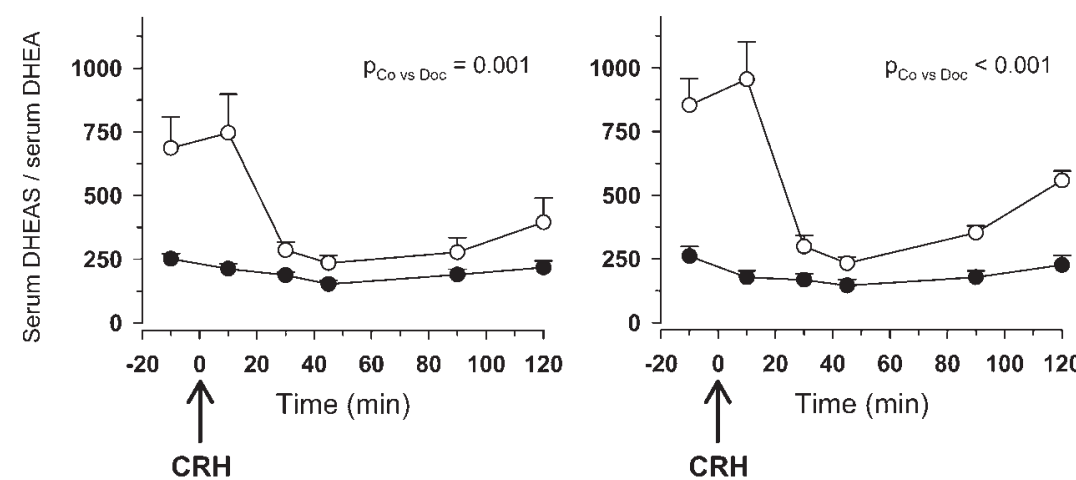

Figure 4 Time course of DHEAS, DHEA, and the ratio of DHEAS/DHEA before and during a hCRH test with $(O)$ or without $(\bullet)$ prior propranolol administration in women and men. The figure depicts serum DHEAS (A, B), serum DHEA (C, D), and the ratio of serum DHEAS/serum DHEA (E, F). The molar ratio has no units. Procedure and explanations for symbols, data presentation, $P$ value, and abbreviations are given in the legend to Fig. 1.

study adrenal hormone cascades. Two other studies with $\beta$-adrenergic antagonists other than propranolol did not demonstrate an increase in either plasma ACTH or serum cortisol $(34,35)$. Similar to studies with $\mathrm{CRH}$ and $\alpha$-adrenergic antagonists, studies with hypoglycemia-induced activation of the HPA axis and administration of $\alpha$-adrenergic antagonists did not change either plasma ACTH or serum cortisol levels $(36-38)$. One very interesting study with i.v. ACTH and prior propranolol administration revealed an

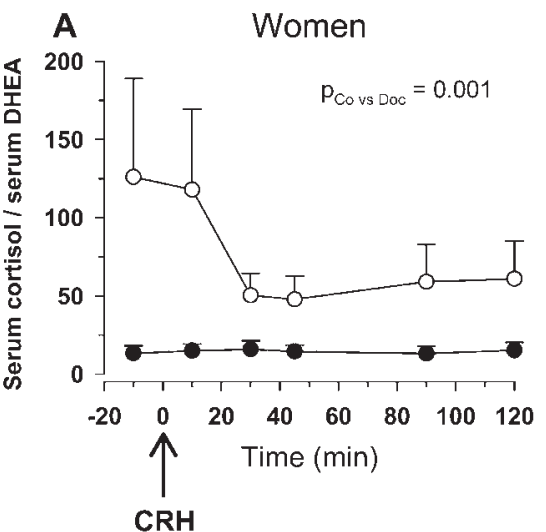

Figure 5 Time course of the ratio of serum cortisol/serum DHEA before and during a $\mathrm{hCRH}$ test with $(\mathrm{O})$ or without $(\bullet)$ prior propranolol administration in women and men. The molar ratio has no units. Procedure and explanations for symbols, data presentation, $P$ value, and abbreviations are given in the legend to Fig. 1. 
increase in serum cortisol (39). Taken together, prior propranolol administration increased serum cortisol independent of the stimulus, whether hypoglycemia, i.v. ACTH, or i.v. CRH. This indicates that under such systemic conditions a sympathetic nervous system (SNS) tone via $\beta$-adrenoceptors decreases serum cortisol. Interestingly, administration of epinephrine to healthy subjects over one hour also reduced serum cortisol levels, whereas short-term administration over 20 min was ineffective (R H Straub, unpublished observation within another study, (40)). Our study adds the information that under such systemic conditions an SNS tone via $\beta$-adrenoceptors also decreases the ratio of cortisol/ACTH, cortisol/17OHP, cortisol/DHEA, and DHEAS relative to DHEA. To our knowledge, no in vitro studies are available which tested the direct influence of $\beta$ - or $\alpha$-adrenergic agonists or antagonists on adrenal DHEA sulfotransferase or DHEAS sulfatase which may have explained the latter phenomenon. One has to mention that none of these effects may be direct on the adrenocortical level but may be more systemic since $\beta$-adrenergic receptors were not found on normal human adrenocortical cells but only on tumor cells $(41-43)$.

At this point, we have to mention that we conducted our study in four different groups of female and male healthy subjects with and without propranolol. It is a disadvantage of our study that we were not able to recruit the same group a second time in a cross-over design. This may have influenced the general serum levels of steroid hormones at baseline and during the $\mathrm{CRH}$ test between the groups. However, we believe that this fact should not have influenced the results to a large extent since the mean age was very similar between the groups and the variation at baseline and during the test was relatively small as indicated by the S.E.M. Furthermore, the effects of propranolol administration are similar in the two series with either female or male subjects.

These data and results of the studies mentioned seem to be at odds when compared with several studies with $\beta$-adrenergic agonists and human and bovine adrenocortical cells in culture. It has been repeatedly demonstrated that stimulation of the $\beta$-adrenoceptor on adrenocortical cells increases cortisol secretion (4449). Furthermore, the group of Bornstein et al. even demonstrated up-regulation of important steroidogenic enzymes such as P450scc, P450c17, P450c21, and P450c11 (47). In another study, they demonstrated that co-culture of bovine adrenocortical cells and chromaffin cells increases cortisol secretion up to 10-fold (49). At the moment, these contrasting findings cannot be explained by our present data and the literature available. One may speculate that additional co-factors must be present in the local microenvironment which lead to these results. Nevertheless, from the perspective of the entire body a $\beta$-adrenergically induced decrease in serum levels of adrenal hormones seems to be obvious.
Above, we mentioned the strong decrease in serum DHEAS in chronic inflammatory and non-inflammatory diseases. In earlier literature on chronic inflammatory diseases, this phenomenon was ascribed to proinflammatory changes of the adrenal microenvironment but no formal proof has ever been presented. In the case of non-inflammatory diseases, proinflammatory immune-mediated changes should not play a role, however, DHEAS serum levels are also low under these conditions. We now propose that SNS hyperactivity may be the common denominator for low levels of DHEAS in inflammatory and non-inflammatory diseases. In both disease groups, SNS hyperactivity has been described (see for example 17-22), and, in this study, systemic inhibition of $\beta$-adrenergic pathways by propranolol on multiple systemic levels leads to an increase in serum DHEAS and to an increased serum DHEAS/serum DHEA ratio.

In conclusion, a $\beta$-adrenergic influence seems to decrease $\mathrm{CRH}$-stimulated cortisol in relation to ACTH and 170HP, and leads to a decrease in DHEAS in relation to DHEA. Although others found $\beta$-adrenergic stimulation of steroid secretion of cultured adrenocortical cells, the overall systemic influence of the SNS via $\beta$ adrenoceptors seems to inhibit adrenal steroids under unstimulated and stimulated conditions. We propose that sympathetic hyperactivity may be the common denominator for low levels of DHEAS in inflammatory and non-inflammatory diseases.

\section{Acknowledgement}

We thank Angelika Gräber for excellent technical assistance.

\section{References}

1 Masi AT, Josipovic DB \& Jefferson WE. Low adrenal androgenicanabolic steroids in women with rheumatoid arthritis (RA): gasliquid chromatographic studies of RA patients and matched normal control women indicating decreased 11-deoxy-17-ketosteroid excretion. Seminars in Arthritis and Rheumatism 198414 $1-23$.

2 Sambrook PN, Eisman JA, Champion GD \& Pocock NA. Sex hormone status and osteoporosis in postmenopausal women with rheumatoid arthritis. Arthritis and Rheumatism $1988 \quad \mathbf{3 1}$ 973-978.

3 Lahita RG, Bradlow HL, Ginzler E, Pang S \& New M. Low plasma androgens in women with systemic lupus erythematosus. Arthritis and Rheumatism 198730 241-248.

4 Deighton CM, Watson MJ \& Walker DJ. Sex hormones in postmenopausal HLA-identical rheumatoid arthritis discordant sibling pairs. Journal of Rheumatology 199219 1663-1667.

5 Wilder RL. Adrenal and gonadal steroid hormone deficiency in the pathogenesis of rheumatoid arthritis. Journal of Rheumatology 199644 (Suppl) 10-12.

6 Cutolo M, Foppiani L, Prete C, Ballarino P, Sulli A, Villaggio B et al. Hypothalamic-pituitary-adrenocortical axis function in premenopausal women with rheumatoid arthritis not treated with glucocorticoids. Journal of Rheumatology 199926 282-288. 
7 Straub RH, Zeuner M, Antoniou E, Schölmerich J \& Lang B. Dehydroepiandrosterone sulfate is positively correlated with soluble interleukin 2 receptor and soluble intercellular adhesion molecule in systemic lupus erythematosus. Journal of Rheumatology 1996 23 856-861.

8 Straub RH, Vogl D, Gross V, Lang B, Schölmerich J \& Andus T. Association of humoral markers of inflammation and dehydroepiandrosterone sulfate or cortisol serum levels in patients with chronic inflammatory bowel disease. American Journal of Gastroenterology $1998932197-2202$.

9 Straub RH \& Cutolo M. Involvement of the hypothalamic-pituitary-adrenal/gonadal axis and the peripheral nervous system in rheumatoid arthritis: viewpoint based on a systemic pathogenetic role. Arthritis and Rheumatism 2001 44 493-507.

10 Dessein PH, Shipton EA, Joffe BI, Hadebe DP, Stanwix AE \& Van der Merwe BA. Hyposecretion of adrenal androgens and the relation of serum adrenal steroids, serotonin and insulin-like growth factor-I to clinical features in women with fibromyalgia. Pain 199983 313-319.

11 Margaux J, Gervy C, De Maertelaer V, Gangij V, Stzeinfeld S \& Appelboom T. Low serum concentration of DHEA sulphate in fibromyalgia. Arthritis and Rheumatism 200144 (Suppl) S70.

12 Moriyama Y, Yasue H, Yoshimura M, Mizuno Y, Nishiyama K, Tsunoda $\mathrm{R}$ et al. The plasma levels of dehydroepiandrosterone sulfate are decreased in patients with chronic heart failure in proportion to the severity. Journal of Clinical Endocrinology and Metabolism 200085 1834-1840.

13 Barrett-Connor E, Khaw KT \& Yen SS. A prospective study of dehydroepiandrosterone sulfate, mortality, and cardiovascular disease. New England Journal of Medicine 1986315 1519-1524.

14 Heinonen PK, Koivula T \& Pystynen P. Decreased serum level of dehydroepiandrosterone sulfate in postmenopausal women with ovarian cancer. Gynecologic and Obstetric Investigation 198723 $271-274$.

15 Stahl F, Schnorr D, Pilz C \& Dorner G. Dehydroepiandrosterone (DHEA) levels in patients with prostatic cancer, heart diseases and under surgery stress. Experimental and Clinical Endocrinology $19929968-70$

16 Lissoni P, Rovelli F, Giani L, Mandala M, Meregalli S, Barni S et al. Dehydroepiandrosterone sulfate (DHEAS) secretion in early and advanced solid neoplasms: selective deficiency in metastatic disease. International Journal of Biological Markers $1998 \quad 13$ $154-157$.

17 Glück T, Oertel M, Reber T, Zietz B, Schölmerich J \& Straub RH Altered function of the hypothalamic stress axes in patients with moderately active systemic lupus erythematosus. I. The hypothalamus-autonomic nervous system axis. Journal of Rheumatology 200027 903-910.

18 Straub RH, Herfarth H, Falk W, Andus T \& Schölmerich J. Uncoupling of the sympathetic nervous system and the hypothalamicpituitary-adrenal axis in inflammatory bowel disease? Journal of Neuroimmunology 2002126 116-125.

19 Martinez-Lavin M, Hermosillo AG, Rosas M \& Soto ME. Circadian studies of autonomic nervous balance in patients with fibromyalgia: a heart rate variability analysis. Arthritis and Rheumatism 199841 1966-1971.

20 Cohen H, Neumann L, Alhosshle A, Kotler M, Abu-Shakra M \& Buskila D. Abnormal sympathovagal balance in men with fibromyalgia. Journal of Rheumatology 200128 581-589.

21 Cohn JN. The sympathetic nervous system in heart failure. Journal of Cardiovascular Pharmacology 198914 S57-S61.

22 Harvie MN \& Campbell IT. Energy balance, cancer and the sympathetic nervous system. European Journal of Cancer 200036 $289-292$.

23 Ehrhart-Bornstein M, Hinson JP, Bornstein SR, Scherbaum WA \& Vinson GP. Intra-adrenal interactions in the regulation of adrenocortical steroidogenesis. Endocrine Reviews 199819 101-143.

24 Tomori N, Suda T, Nakagami Y, Tozawa F, Sumitomo T, Ushiyama $\mathrm{T}$ et al. Adrenergic modulation of adrenocorticotropin responses to insulin-induced hypoglycemia and corticotropin-releasing hormone. Journal of Clinical Endocrinology and Metabolism 1989 $6887-93$.

25 Delitala G, Trainer PJ, Oliva O, Fanciulli G \& Grossman AB. Opioid peptide and alpha-adrenoceptor pathways in the regulation of the pituitary-adrenal axis in man. Journal of Endocrinology 1994141 $163-168$.

26 Jezova-Repcekova D, Klimes I, Jurcovicova J \& Vigas M. Effect of adrenergic receptor blockade on cortisol and GH response to insulin-induced hypoglycemia in man. International Journal of Clinical Pharmacology and Biopharmacy 197917 64-67.

27 Schluter KJ, Aellig WH, Petersen KG, Rieband HC, Wehrli A \& Kerp L. The influence of beta-adrenoceptor blocking drugs with and without intrinsic sympathomimetic activity on the hormonal responses to hypo- and hyperglycaemia. British Journal of Clinical Pharmacology 198213 407S-417S.

28 Straub RH, Konecna L, Hrach S, Rothe G, Kreutz M, Schölmerich J et al. Serum dehydroepiandrosterone (DHEA) and DHEA sulfate are negatively correlated with serum interleukin-6 (IL-6), and DHEA inhibits IL-6 secretion from mononuclear cells in man in vitro: possible link between endocrinosenescence and immunosenescence. Journal of Clinical Endocrinology and Metabolism 1998 $832012-2017$.

29 Ligthart GJ, Corberand JX, Fournier C, Galanaud P, Hijmans W, Kennes B et al. Admission criteria for immunogerontological studies in man: the SENIEUR protocol. Mechanisms of Ageing and Development 198428 47-55.

30 Straub RH, Hall C, Kramer BK, Elbracht R, Palitzsch KD, Lang B et al. Atrial natriuretic factor and digoxin-like immunoreactive factor in diabetic patients: their interrelation and the influence of the autonomic nervous system. Journal of Clinical Endocrinology and Metabolism $1996813385-3389$.

31 Barone RM, Shamonki IM, Siiteri PK \& Judd HL. Inhibition of peripheral aromatization of androstenedione to estrone in postmenopausal women with breast cancer using delta 1-testololactone. Journal of Clinical Endocrinology and Metabolism $1979 \quad \mathbf{4 9}$ 672-676.

32 Nestler JE, McClanahan MA, Clore JN \& Blackard WG. Insulin inhibits adrenal 17,20-lyase activity in man. Journal of Clinical Endocrinology and Metabolism 199274 362-367.

33 Lager I, Jagenburg R, von Schenck H \& Smith U. Effect of betablockade on hormone release during hypoglycaemia in insulindependent diabetics. Acta Endocrinologica 198095 364-371.

34 Viberti GC, Keen H \& Bloom SR. Beta blockade and diabetes mellitus: effect of oxprenolol and metoprolol on the metabolic, cardiovascular, and hormonal response to insulin-induced hypoglycemia in normal subjects. Metabolism 198029 866-872.

35 Lantz B, Paillard F, Nunez E \& Assan R. Short tertatolol treatment does not impair the hormone and metabolic responses to exercise and hypoglycemia in diabetics. Hormone and Metabolic Research $198921561-565$.

36 Cuneo RC, Livesey JH, Nicholls MG, Espiner EA \& Donald RA. Effects of alpha-1 adrenergic blockade on the hormonal response to hypoglycaemic stress in normal man. Clinical Endocrinology $1987261-8$

37 Cuneo RC, Livesey JH, Nicholls MG, Espiner EA \& Donald RA. Effects of alpha-2 adrenoreceptor blockade by yohimbine on the hormonal response to hypoglycaemic stress in normal man. Hormone and Metabolic Research 198921 33-36.

38 Spencer GS \& Lister D. The effect of alpha-adrenergic blockade on the release of ACTH and cortisol in vivo. Hormone and Metabolic Research $198315230-232$.

39 Belkien L, Baumann J, Schirpai M \& Oelkers W. Propranolol enhances the effect of ACTH on plasma cortisol, but not on aldosterone in man. Journal of Endocrinological Investigation 19836 341-345.

40 Straub RH, Kittner J, Heijnen CJ, Schedlowski M, Schmidt RE \& Jacobs R. Infusion of epinephrine decreases serum levels of cortisol and 17-hydroxyprogesterone in patients with rheumatoid arthritis. Journal of Rheumatology 200229 1659-1664.

41 Hirata Y, Uchihashi M, Sueoka S, Matsukura S \& Fujita T. Presence of ectopic beta-adrenergic receptors on human adrenocortical 
cortisol-producing adenomas. Journal of Clinical Endocrinology and Metabolism 198153 953-957.

42 Katz MS, Kelly TM, Dax EM, Pineyro MA, Partilla JS \& Gregerman RI. Ectopic beta-adrenergic receptors coupled to adenylate cyclase in human adrenocortical carcinomas. Journal of Clinical Endocrinology and Metabolism $198560900-909$.

43 Lacroix A, Tremblay J, Rousseau G, Bouvier M \& Hamet P. Propranolol therapy for ectopic beta-adrenergic receptors in adrenal Cushing's syndrome. New England Journal of Medicine 1997337 1429-1434.

44 Walker SW, Lightly ER, Milner SW \& Williams BC. Catecholamine stimulation of cortisol secretion by 3-day primary cultures of purified zona fasciculata/reticularis cells isolated from bovine adrenal cortex. Molecular and Cellular Endocrinology 198857 139-147.

45 Walker SW, Lightly ER, Clyne C, Williams BC \& Bird IM. Adrenergic and cholinergic regulation of cortisol secretion from the zona fasciculata/reticularis of bovine adrenal cortex. Endocrine Research $199117237-265$.

46 Ehrhart-Bornstein M, Bornstein SR, Trzeclak WH, Usadel H, Guse-Behling H, Waterman MR et al. Adrenaline stimulates cholesterol side-chain cleavage cytochrome P450 mRNA accumulation in bovine adrenocortical cells. Journal of Endocrinology 1991131 R5-R8.

47 Guse-Behling H, Ehrhart-Bornstein M, Bornstein SR, Waterman MR, Scherbaum WA \& Adler G. Regulation of adrenal steroidogenesis by adrenaline: expression of cytochrome $\mathrm{P} 450$ genes. Journal of Endocrinology 1992135 229-237.

48 Bornstein SR, Haidan A \& Ehrhart-Bornstein M. Cellular communication in the neuro-adrenocortical axis: role of vasoactive intestinal polypeptide (VIP). Endocrine Research 199622 $819-829$.

49 Haidan A, Bornstein SR, Glasow A, Uhlmann K, Lubke C \& Ehrhart-Bornstein M. Basal steroidogenic activity of adrenocortical cells is increased 10-fold by coculture with chromaffin cells. Endocrinology $1998139772-780$.

Received 29 April 2002

Accepted 12 September 2002 